\title{
Age, Gender and Culture as Correlates of Use of Knowledge Management Systems in Makerere University
}

\author{
F.E.K. Bakkabulindi and B. Sekabembe \\ East African Institute of Higher Education Studies \& Development, Makerere University \\ fekbakkabulindi@isae.mak.ac.ug
}

\begin{abstract}
The purpose of the study was to establish which of (i) age (ii) gender and (iii) organizational culture is a correlate of use of knowledge management systems (KMS) among teachers, senior administrators and postgraduate students in Makerere University. The study was a co-relational and cross-sectional survey biased to the quantitative approach, involving 444 respondents from the University, from whom primary data were collected using a self-administered questionnaire, and analysed using summary statistics (e.g. means, standard deviations), t-test, Correlation and Multiple Regression Analyses. The study found that while age and gender were unimportant, organizational culture significantly correlated with KMS use among teachers, senior administrators and postgraduate students in the University. The study thus concluded that organizational culture must be improved if KMS use in Makerere University is to improve, leading to the recommendation that all stakeholders look into the possibility of improving organizational culture in the respective units in the University as a measure of enhancing KMS use.
\end{abstract}

Keywords: Knowledge management, innovation, gender, organizational culture.

\section{Introduction}

Turban, Aronson, Liang \& Sharda (2007) define Knowledge Management (KM) as the systematic and active management of ideas, information, and knowledge residing in an organisation's employees, defining a Knowledge Management System (KMS) as Information and Communication Technology (ICT) that makes KM available throughout an organization. In other words, KMS are ICT tools that facilitate the creation, storage, transfer and application of organizational knowledge. Turban et al (2007) stress this definition by observing that a KMS is the use of modern ICT (e.g. the Internet, Intranets and extranets) to systematize, enhance, and expedite intra- and inter- firm knowledge management. Turban et al. (2007) observe however that: "encouraging employees to use a KMS, both for contributing knowledge and for seeking knowledge, can be difficult" (p. 487). This is particularly so in Africa, as is observed by Sebandeke (personal communication, June 23, 2009) to the effect that "whereas knowledge management and all associated best practices have been well received and embraced by the Western World, Africa seems to have a long way to go". 
This observation happens to be true of Makerere University where use of computers and/ or ICT and other KMS tools, has consistently been reported to be low (e.g. Agaba, 2003; Makerere University, 2000; Niwe, 2000; Nsobya, 2002). For example, Makerere University (2000) observes that most departments in the University, both academic and administrative, depending on manual systems, with little use being made of computers in admission and registration, examinations, students' records, finance and accounting, estates, library management, personnel, office systems and so on. In addition, e-mail use and Internet access are minimal. Moreover, most sections of the University are using ageing PCs with old versions of software. Failure to use these KMS tools, implies that Makerere teachers, administrators and students are missing the opportunity afforded by KMS namely "to help an organization cope with turn over, rapid change, and down sizing by making the expertise of the organization's human capital widely accessible" (Turban et al., 2007: 484).

As suggested by Sebandeke (personal communication, June 23, 2009), "it is therefore... appropriate enough to set off' by trying to isolate the reasons why African institutions such as Makerere University are slow to embrace use of KMSs. The theoretical basis for this study is Turban et al. (2007) who note that several past studies (e.g. Riege, 2005) have identified a number of possible reasons why people do not like to share knowledge, including differences in terms of age, gender and organizational culture. Hence this study appraising the role of the three independent variables on KMS use by teachers, senior administrators and postgraduate students in Makerere University. The following section relates each of the three independent variables in the study, to use of innovations, basing on the fact that KMSs are an innovation, in conformity with the assertion that "knowledge management... is a ... new form of collaborative computing" (Turban et al., 2007: 480). It is still in line with Turban et al (2007)'s observation that KMS, that is the "application of ICT tools to facilitate the creation, storage, transfer and application of... organizational knowledge is a new and major initiative in organizations" (p. 481).

\section{Related Literature}

\subsection{Age and Use of Innovations}

Schiffman \& Kanuk (2004) observe that it is reasonable to assume that age of the consumer innovator is related to the specific product category in which the consumer innovates, with consumer innovators tending to be younger than either late adopters or innovators because many of the products selected for research attention (e.g. fashion, automobiles) are particularly attractive to young consumers. Age is also theorized to be important in adoption of health and/or demographic innovations such as family planning (Bonabana, 2000), contraception (Karugaba, nd) and health service utilization (Mayanja, 2001). Age is also theorized to be important in the adoption of agricultural innovations, although there are two conflicting explanations for this: For example Basisa (1999) points out that while older farmers may have more experience, education and farm resources which factors can be an incentive to try out a 
technology, young farmers tend to have more schooling and exposure to new ideas that may help to adopt a technology, which suggests an inconclusive debate and hence gap on this issue.

A few past studies on age and innovation adoption are now given. Natukunda (1998) found age to be negatively associated with knowledge and ever-use of contraception in both Central and Northern Uganda, while Turyaheebwa (2000), found that in Kampala District, women's attitudes towards family planning became more favourable with age. Byarugaba (1998) reported finding age as a factor with a significant relationship with modern contraceptive use in his study of selected socioeconomic and demographic determinants of modern contraceptive use in Western Uganda. Ehikhamenor (1999) found age as having no influence on the level of ICT cognition or knowledge among 116 newly admitted postgraduates in information related programmes (i.e. information science; communication and language arts; and library archival and information studies in Nigeria. Thus while many of the above studies (e.g. Naturinda, 1998) showed a negative correlation between age and innovation adoption, others found a positive relationship (e.g. Turyaheebwa, 2000) yet others (e.g. Ehikhamenor, 1999) did not find any relationship. Such contradicting findings call for more studies to establish the truth. Further, of all the studies reviewed, only one (Ehikhamenor, 1999) was on the context of an academic institution, but not Makerere. Thus the empirical question remained for this study to answer; What effect did age have on KMS use in Makerere University if at all, explaining why age was hypothesized as a negative correlate of KMS use in Makerere University in this study, given that no earlier study had addressed itself to the issue.

\subsection{Gender and Use of Innovations}

Gender comprises a range of differences between men and women extending from the biological to the social practitional roles a woman has to play like caring for the children, cooking, fetching water and firewood, in addition to cultivation may hinder her from easily adopting to technology use. According to Kato (2000), the marginalization of women in regard to technology adoption and transfer is reinforced by the African cultural system which requires women to remain at home while husbands attend seminars, yet they do not always teach women what they have learnt in extension meetings. Women do not have access to the key productive resources such as capital, as well as being underprivileged in education and knowledge. Mwebesa (1997) observes that technological changes are not usually aimed at women at all, and that large scale development projects and their attendant technology rarely include policy regarding women; that sexist bias was the most important factor explaining the inability of women to take advantage of new technology offered; that appropriate technology programmes reveal that many projects do not achieve positive results for women's lives; that in many projects, even technology introduced for the benefit of women has been co-opted by men for their own use.

Any past studies on gender and innovation adoption? Mbabazi (2002) found sex as one of the variables significantly associated with reasons against condom use among adolescents in Central and Eastern Uganda, while Lubanga-Kiwanuka (1998) found gender as one of the factors influencing the adoption of new technologies in her study 
of the factors influencing the adoption of new technologies of integrating and utilizing fruit trees in the farming system of Mukono District, Uganda. Another study (Sseguya, 2000) reports empirically finding gender as one of the factors significantly related to the adoption of soil fertility management technologies in banana-based agriculture of Lake Victoria Basin. Lewis (1995 cited in Obbo, 2001) is reported as empirically finding that internet content design, use, and so on are predominantly male, which finding was corroborated by Mburu, Massimo and Mutua (2000) who reported a similarly gender biased empirical finding in their study on Internet use in Gaborone City, Botswana.

However, Luwedde (1997) found that gender of farmer was not a significant factor in adoption of improved post-harvest technologies of tomatoes among small-scale farmers in Mukono District, Uganda. Another similar negative finding was by another study (Nakiganda, 2004) which concluded that gender (or sex) was not an important factor affecting use of agro-chemicals in Buikwe County, Mukono District, Uganda. Also, Ehikhamenor, (1999) found sex as having no influence on the level of ICT cognition or knowledge among 116 newly admitted postgraduates in information related programmes (i.e. information science; communication and language arts; and library archival and information studies) in Nigeria. Thus while many studies showed gender as an important factor in innovation adoption, others (Ehikhamenor, 1999; Nakiganda, 2004) did not show any, suggesting that the correlation between these two variables is far from certain, hence the need for this study to test the correlation between gender and use of KMSs.

\subsection{Organisational Culture and Use of Innovations}

An organisation's ability to learn, develop memory, and share knowledge is dependent on its culture (Turban etal, 2007). Kizza (2003) argues that organisational culture is key to understanding why some firms succeed in implementing their strategies while others fail. Culture, a concept developed from anthropology is difficult to define or explain precisely (Mullins, 2002; Ndibalekera, 2002; Ssentamu, 2001). Nevertheless quite a few suggestions have come up. It has variously been conceptualized as; "how things are done around here" (Mullins, 2002: 802; Ndibalekera, 2002: 14); as the "underlying assumptions about the way work is performed"; "what is acceptable and not acceptable"; "what behaviour and actions are encouraged and discouraged" (Mullins, 2002: 802); as the "collective programming of the mind which distinguishes the members of one organisation from another" (Ndibalekera, 2002: 14-15); as a "pattern of shared basic assumptions" (Turban etal, 2007: 487). Kizza (2003) observes that if change is to succeed in an organisation, one needs to understand the culture that is to be changed. If the proposed changes contradict cultural biases and traditions, the changes will be difficult to embed in the organisation.

Since cultures are difficult to change, organizational culture is among the sources of resistance to change (Kizza, 2003; Rogers, 2003). Turban etal (2007) seem to concur with the above observations when they make an assertion of much significance in the current study to the effect that "an organizational culture that does 
not foster sharing can severely cripple a KM effort" (p. 487). Any empirical studies on organizational culture and innovation adoption? Korpella (1996) set out to test the hypothesis of traditional culture as the key explanatory factor for organisational obstacles to ICT in developing countries. Using the case of the Yoruba ethnic group in Nigeria with a fairly uniform and distinct culture, he showed that that hypothesis was false, naïve, arrogant and led to dubious recommendations to developing countries, hence concluding that the differences in ICT adoption were not due to culture (indeed, according to him, there was no "culture of developing countries") but of political economy, a legacy of colonialism. Sentamu (2001) was a study on why the introduction of ICT in National Water \& Sewage Corporation, NWSC in Uganda had not yielded significant changes in performance, which revealed a strong significant relationship between organizational culture prevalent in an organization and ICT adoption and hence called for the need to harmonize organizational culture and ICT adoption to enhance performance.

Mugweri (2000) in his assessment of the opportunities and challenges of exploiting ICT networks to improve efficiency and effectiveness in government operations using the case of the Ministry of Finance, Planning \& Economic Development (MFPED), Uganda, established organisational culture to be one of the factors curtailing ICT adoption, when he, for example reported finding that the cultural context in MFPED was inimical to optimal exploitation of ICT networks. Dawa (2004) reported an empirical case of where faculty culture impeded ICT adoption when he reported that in 1998 the Faculty of Law, Makerere University sought to have its academic and administrative functions computerized by employing a technology consultant. However according to the Report of the Dean of Law Faculty of April 2000, the Computer Management Committee resolved to terminate the technologist's contract because he had not developed any system. In response the technologist reportedly described the environment or culture in the Faculty of Law as having been hostile and hence deterring his ability to fulfill his terms of reference, thus suggesting that the culture of a major Faculty in Makerere was deterring adoption of ICT. From the above empirical cases this study still had major questions to answer; (i) Was the consultant used by the Faculty of Law sincere in blaming the Faculty's poor ICT culture for the ICT venture failure? (ii) If he was, was the same true in the other units in Makerere University? That explains why organizational culture was used as a probable explanation of KMS use in Makerere University in this study.

\section{Hypotheses}

This section will seek validity of the following hypotheses:

(i) Age negatively affects KMS use by teachers, senior administrators and postgraduate students in Makerere University.

(ii) Gender affects KMS use by teachers, senior administrators and postgraduate students in Makerere University, with male performing better than females.

(iii) Organisational culture enhances KMS use by teachers, senior administrators and postgraduate students in Makerere University. 


\section{Method}

Using a quantitative correlational survey design, data were collected using a selfadministered questionnaire with four background questions of relevance in this Paper, namely age, gender and income level. It had five items on organizational culture ( $\alpha=$ $.8828)$; and another 12 items on KMS use $(\alpha=.8918)$. According to Cronbach's Alpha Coefficient Test (Cronbach, 1971), the questionnaire was reliable for the study as both alpha coefficients were above 0.5. Using the said questionnaire, data were collected from a sample of 145 teachers, 124 senior administrators and 175 postgraduate students in Makerere University: other details about respondents are given in Table 1, which suggests that the typical respondent was aged between 30 and 40 years (39\%), a male (66\%), postgraduate student (39\%) and of medium income (64\%). The data were analysed using summary statistics (e.g. means, standard deviations), t-test, Correlation and Multiple Regression Analyses.

Table 1. Descriptive statistics on respondents' background

\begin{tabular}{|l|l|c|c|}
\hline Description & Category & Frequency & Percentage \\
\hline \multirow{3}{*}{ Age group in years } & Up to 30 & 148 & 35.8 \\
\cline { 2 - 4 } & 30 but below 40 & 161 & 39.0 \\
\cline { 2 - 4 } & 40 and above & 104 & 25.2 \\
\hline \multirow{3}{*}{ Gender } & Female & 147 & 33.9 \\
\cline { 2 - 4 } & Male & 287 & 66.1 \\
\hline Category of respondent & Teaching & 145 & 32.7 \\
\cline { 2 - 4 } & Senior administrator & 124 & 27.9 \\
\cline { 2 - 4 } & Postgraduate student & 175 & 39.4 \\
\hline \multirow{3}{*}{ Income level } & Low & 132 & 31.1 \\
\cline { 2 - 4 } & Medium & 271 & 63.8 \\
\cline { 2 - 4 } & High & 22 & 5.2 \\
\hline
\end{tabular}

\section{Description of Dependent Variable: KMS Use}

Knowledge management systems (KMS) use was a multi-dimensional variable made of twelve questions or items, each scaled $1=$ Very rarely or never, including never heard of it; 2 = Rarely use; $3=$ Neither rarely nor regularly; $4=$ Regularly; and $5=$ Very regularly. Pertinent descriptive statistics are given in Table 2:

According to Table 2, e-mail use had the highest sample mean, of over 4, followed by surfing use, suggesting regular use of these KMSs by respondents. African Virtual University (AVU) and video conferencing had the lowest sample means slightly above 1 (i.e. 1.56 and 1.48), suggesting that they were very rarely or never used by the majority of respondents. To get an overall picture of how respondents rated themselves on KMS use, an average index "KMS" was computed from the 12 
Table 2. Descriptive statistics on KMS use

\begin{tabular}{|l|r|c|}
\hline Indicator of KMS use & Mean & Standard deviation \\
\hline LAN in your school, faculty or department & 3.14 & 1.57 \\
\hline WAN in Makerere University & 3.03 & 1.56 \\
\hline Africa Virtual University & 1.56 & 1.07 \\
\hline Email & 4.21 & 1.89 \\
\hline Web surfing & 4.00 & 1.27 \\
\hline Bulletin board, mailing lists, discussion groups & 2.49 & 1.46 \\
\hline Computer conferencing systems & 1.67 & 1.06 \\
\hline Video conferencing systems & 1.48 & 0.90 \\
\hline Electronic journals, newsletters (e.g. in Main Lib) & 2.43 & 1.41 \\
\hline Electronic databases & 2.23 & 1.35 \\
\hline On-line library catalogs & 2.17 & 1.33 \\
\hline Other e-facilities & 1.68 & 1.19 \\
\hline
\end{tabular}

questions or items in Table 2 and found to have a mean $=2.38$, which as per the used scale was suggesting that overall, the majority of respondents rarely use KMS facilities.

\section{Bivarite Analysis}

In this Section, bivariate or two-variable analyses are used to perform a preliminary test of hypotheses in the study:

\subsection{Age and KMS Use}

The first hypothesis in the study was that age was inversely related to KMS use among teachers, senior administrators and postgraduate students in Makerere University. Respondents were thus prompted to state their ages in years, which turned out to have a mean of 36 and median of 35 suggesting that respondents were above youthful age of 35 generally because only postgraduate students, administrators and lecturers were involved. The fact that the mean and median are almost same implies normality of distribution, despite slight skew $(\mathrm{Sk}=.769)$. The ages ranged from a minimum of 22 to a maximum of 69. Pearson's Linear Co-relation Coefficient was used to co-relate age with KMS use, yielding $r=-0.083, p=0.411$, leading to acceptance of the null hypothesis to the effect that age was not significantly inversely related with KMS use among teachers, senior administrators and postgraduate students in Makerere University at the five percent level of significance ( $p>0.05)$.

\subsection{Gender and KMS Use}

The second objective in the study intended to establish the effect of gender on KMS use by teachers, senior administrators and postgraduate students in Makerere University from which it was hypothesized that gender affects KMS use, with males 
being better. Given that the study wished to relate a numerical dependent variable (KMS use) with a binary categorical independent variable (gender), a t-test was suitable to test the null hypothesis. Table 3 gives the pertinent results:

Table 3. Descriptive and t-test results on KMS use by gender

\begin{tabular}{|l|c|c|c|c|c|}
\hline Gender & Count & Mean & $\begin{array}{l}\text { Standard } \\
\text { deviation }\end{array}$ & t value & $\begin{array}{c}\text { Sig. or } \mathbf{p} \\
\text { value }\end{array}$ \\
\hline Female & 37 & 2.54 & .82 & 1.504 & .136 \\
\hline Male & 67 & 2.27 & .87 & & \\
\hline
\end{tabular}

Means in Table 3 suggest that females (mean $=2.54)$ were better than males (Mean $=2.27$ ) at KMS use. However the pertinent $\mathrm{t}$ value (1.504) is small because its p value (0.136) exceeds the benchmark sig. $\alpha=0.05$. Thus at the five percent, we accept the null hypothesis to the effect that gender did not affect KMS use by teachers, senior administrators and postgraduate students in Makerere University.

\subsection{Organisational Culture and KMS Use}

The study wanted to see the influence of organizational culture on KMS use in Makerere, conceptualizing organizational culture as the extent to which the respondent agreed that their unit is change-oriented, innovative, progressive, ensures participation of all, and ensures organisational learning (five items), using a scale ranging from a minimum of one for strongly disagree, to a maximum of five for strongly agree. Table 4 gives resulting descriptive statistics:

Table 4. Descriptive statistics on organisational culture

\begin{tabular}{|l|c|c|}
\hline Indicator of organizational culture & Arithmetic mean & Standard deviation \\
\hline Unit is change-oriented & 3.12 & 1.29 \\
\hline Unit is innovative & 3.30 & 1.22 \\
\hline Unit is progressive & 3.44 & 1.20 \\
\hline Unit ensures participation of all & 2.92 & 1.24 \\
\hline Unit ensures organizational learning & 2.91 & 1.29 \\
\hline
\end{tabular}

It is noteworthy from Table 4 that all the five cultural constructs or items recorded means around three (i.e. median score), which suggests that as far as these items are concerned, cultures in the respective units in Makerere were viewed fairly by respondents. To get an overall picture of how respondents rated organizational culture in their respective units in Makerere University, an average index "Culture" was computed from the five questions or items in Table 4 and found to have a mean = 3.13, which as per the used scale was suggesting that overall, the majority of respondents rated their respective cultures as fair. When this index was correlated with the aggregate KMS use index, it yielded a significantly positive correlation, 
$r=0.313^{* *}(p=0.002)$, suggesting that the better the organisational culture of the unit in Makerere University a respondent is in, the higher the expected level of KMS use of that respondent, at the one per cent of significance $(p<0.01)$.

\section{Multivariate Analysis}

Bivariate analyses in Section 6.0 suggested that of the three independent variables (age, gender and organizational culture) only organizational culture seemed a potential correlate of KMS use among lecturers, administrators and postgraduates in Makerere University. However to rank order the three variables as correlates of KMS use, a more powerful multivariate tool, Multiple Regression Analysis, which takes into account simultaneous relationships of the many variables thus documenting collective effects and accounting for potentially spurious factors (Sweet \& GraceMartin, 2003) was employed. But before fitting the multiple regression model, independent variables were treated as follows: Being a continuous variable, age was used in the model as given by the respondents with no modification; because of its categorical nature, a dummy was created from Table 3 for gender $(0=$ female; $1=$ male); organizational culture being a continuous variable, was used in the model as given by the respondents with no modification. Hence a multiple regression analysis of the aggregate KMS use index (KMS) on the three independent variables, yielded the results in Table 5:

Table 5. Regression results on KMS use on age, gender \& organizational culture

(a) ANOVA table

\begin{tabular}{|c|c|c|}
\hline F statistic & Significance level & Adjusted R square \\
\hline 4.71 & .004 & 0.109 \\
\hline
\end{tabular}

(b) Coefficients

\begin{tabular}{|l|c|c|}
\hline Independent variable & Beta, $\boldsymbol{\beta}$ & Sig. or $\boldsymbol{p}$ value \\
\hline Age & -0.136 & 0.188 \\
\hline Gender dummy $(0=$ Female; $1=$ Male $)$ & -0.066 & 0.520 \\
\hline Organisational culture & 0.352 & 0.001 \\
\hline
\end{tabular}

Part (a) of Table 5 suggests that the three independent variables considered, were collectively good explanatory variables of KMS use among lecturers, administrators and postgraduates in Makerere University $(\mathrm{F}=4.71 ; \mathrm{p}=0.004<0.01)$, although accounting for less than $11 \%$ of the variation in the aggregate KMS use index (Adjusted R square $=0.109$ ). Table 5 (part b) further suggests that of the three independent variables, only organizational culture was a significant correlate of KMS use at the one percent level of significance (its $p=0.001<0.01$ ). 


\section{Discussion, Conclusions and Recommendations}

The study has suggested that KMS use among lecturers, administrators and postgraduates in Makerere University is low, corroborating earlier researchers who came to similar findings about Makerere in the areas of utilization of computers in the management of students' information such as admissions (Nakaye, 1998; Zziwa, 2001); Internet utilisation by teaching staff as source of information (Agaba, 2003; Niwe, 2000); student participation in ICT usage and management (Nassanga, 2001), and teaching (Nyakoojo, 2002). Now the discussion, conclusions and recommendations turn to the influence of each independent variable on KMS use.

\subsection{Age and KMS Use}

The study findings disagreed with the initial hypothesis that age is negatively related to KMS use among teachers, senior administrators and postgraduate students in Makerere University, inconsistent with several past studies (e.g. Byarugaba, 1998; Natukunda, 1998; Turyaheebwa, 2000) but consistent with others (e.g. Ehikhamenor, 1999). The finding dismisses theoretical assertions such as that by Schiffman and Kanuk (2004) to the effect that age is an important correlate of innovation adoption, with consumer innovators tending to be younger than late adopters or innovators. In conclusion, age proved an unimportant correlate of KMS use among teachers, senior administrators and postgraduate students in Makerere University. It is thus recommended that to improve KMS use in the UNiversity, stakeholders such as University Management should give equal training, exposure and encouragement with respect to KMS use to all teachers, senior administrators and postgraduate students without regard to age.

\subsection{Gender and KMS Use}

While the study set out on the premise that females were at a disadvantage as far as KMS use is concerned, the study findings proved otherwise, a finding similar to that of Ehikhamenor (1999), but disagreeing with others (e.g. Mburu, Massimo \& Mutua, 2000). The possible explanation for the study finding is that levels of KMS use are so low among teachers, senior administrators and postgraduate students in Makerere University that they cut across the gender divide. In other words, both males and females in the University are equally poor at KMS use. The study thus concludes that males are not better at KMS use among teachers, senior administrators and postgraduate students in Makerere University: hence the recommendation that both male and female teachers, senior administrators and postgraduate students in the University be given equal training, exposure and/ or encouragement with respect to KMS.

\subsection{Organisational Culture and KMS Use}

The study set out to test the relevance of good organizational culture in enhancing KMS use in Makerere University, which hypothesis was supported by the findings. 
This finding, while inconsistent with some past studies (e.g. Korpella, 1996), it was at par with a host of others (Dawa, 2004; Mugweri, 2000; Ssentamu, 2001). The finding thus strengthens the theoretical assertion that organizational culture is that does not foster sharing can severely cripple a knowledge effort (Kizza, 2003; Turban, et al., 2007). The findings thus lead to the conclusion that organizational culture is a positive correlate of KMS use and hence the recommendation that if KMS use is to take root in Makerere University, then the respective units in the University should enhance their organizational cultures.

\section{References}

Agaba, D.: Utilization of Makerere University Library electronic information resources by academic staff: challenges and the way forward. Unpublished Masters (of Sc in Info Sc) dissertation, Makerere University, Kampala, Uganda (2003)

Basisa, M.C.: Farmer characteristics influencing adoption of organic farming techniques among partner farmers of Africa 2000 Network in Kasese District Uganda. Unpublished Masters (of Sc. Agric Ext./ Educ.) dissertation, Makerere University, Kampala, Uganda (1999)

Bonabaana, C.D.: Use of family planning methods in Mbarara District. Unpublished Bachelors (of Stat.) dissertation, Makerere University, Kampala, Uganda (2000)

Byarugaba, R.: Socio-economic and demographic determinants of modern contraceptive use in Uganda: Study of Western Region. Unpublished Masters (of Arts, Demo.) dissertation, Makerere University, Kampala, Uganda (1998)

Cronbach, L.J.: Test validation. In: Thorndike, R.L. (ed.) Educational Measurement, pp. 443597. American Council on Education, Washington, D.C (1971)

Dawa, S.: Information technology personnel competencies and computer-based Information system usability in Uganda. Unpublished Masters (of Bus. Adm.) dissertation, Makerere University, Kampala, Uganda (2004)

Ehikhamenor, F.A.: Cognitive information foundation of university students: Index of ICT in Nigeria. Information Technology for Development 8(3), 134-144 (1999)

Karugaba, R.: Factors influencing contraceptive use: A case study of Buhunga Parish in Rukungiri District. Unpublished Bachelors (of Arts, Sociology) dissertation, Makerere University, Kampala, Uganda

Kato, E.: Analysis of factors affecting adoption of K131 bean variety by women groups in Luuka County, Iganga District, Uganda. Unpublished Bachelors (of Librarianship \& Info. Sc.) dissertation, Makerere University, Kampala, Uganda (2000)

Kizza, J.: Culture, management styles and management of change in public education institutions: A case of national teachers' colleges in Uganda. Unpublished Masters (of Bus. Adm.) dissertation, Makerere University, Kampala, Uganda (2003)

Korpella, M.: Traditional culture or political economy? On the root causes of organizational obstacles of IT in developing countries. Information Technology for Development 7(1), 2942 (1996)

Lubanga-Kiwanuka, R.: Factors influencing adoption of new technologies of integrating and utilizing fruit trees in the farming system of Mukono District. Unpublished Masters (of Agric. Ext./ Educ.) dissertation, Makerere University, Kampala, Uganda (1998)

Luwedde, I.: Factors influencing adoption of improved post-harvest technologies of tomatoes among small-scale farmers in Mukono District. Unpublished Masters (of Agric. Ext./ Educ.) dissertation, Makerere University, Kampala, Uganda (1997) 
Makerere University, Strategic Plan, 2000/ 01- 2004/05. Kampala: Planning \& Development Department (2000)

Mayanja, S.P.: Barriers to utilization of mother-to-child package in selected districts in Uganda. Unpublished Masters (of Arts, Demo.) dissertation, Makerere University, Kampala, Uganda (2001)

Mbabazi, K.G.: Factors hindering condom use among adolescents in Uganda: A case of Central and Eastern, Uganda. Unpublished Masters (of Arts, Demo.) dissertation, Makerere University, Kampala, Uganda (2000)

Mburu, P.T., Massimo, S.K., Mutua, K.: How are internet facilities being used in Botswana? Makerere Business Journal (pp. 81-98): Summary of papers presented at the 7th Annual International Management Conferenceon the theme: Coping with economic and technological change in the New Millennium, December 4 to 7 , organized by Makerere University Business School, Kampala (2000)

Mugweri, R.A.: Assessment of opportunities and challenges of exploiting ICT networks to improve efficiency and effectiveness in government operations: A case study of MFPED. Unpublished Masters (of Sc in Info Sc.) dissertation, Makerere University, Kampala, Uganda (2002)

Mullins, L.J.: Management and organization behavior. Pitman, London (2002)

Mwebesa, J.: Impact of technological innovation on rural women's agricultural activities: A case of the solar drier. Unpublished Masters (of Arts, Women Studies) dissertation, Makerere University, Kampala, Uganda (1997)

Nakaye, A.: Information utilization in managing admissions of students at Makerere University. Unpublished Masters (of Public Adm. \& Mgt.) dissertation, Makerere University, Kampala, Uganda (1998)

Nakiganda, A.P.N.: Socio-economic factors influencing use of agro-chemicals in vegetable production and implications for land management in Buikwe County, Mukono District. Unpublished Masters (of Arts, Land Use \& Regional Development) dissertation, Makerere University, Kampala, Uganda (2004)

Nassanga, M.: Students' participation in ICT usage and management: a case study of EASLIS. Unpublished Bachelors (of Librarianship and Info Sc.) dissertation, Makerere University, Kampala, Uganda (2001)

Natukunda, D.: Socio-economic and demographic factors influencing use of contraceptives in Uganda: A comparative study of Central \& Northern Regions. Unpublished Masters (of Arts, Demo) dissertation, Makerere University, Kampala, Uganda (1998)

Ndibalekera, L.S.: Organisational culture, organisation learning and decision making: The case of World Vision. Unpublished Masters (of Bus. Adm.) dissertation, Makerere University, Kampala, Uganda (2002)

Niwe, M.: Assessing the potential of using Internet as tool for meeting information needs of academic staff in Makerere University. Unpublished Masters (of Sc in Info Sc) dissertation, Makerere University, Kampala, Uganda (2000)

Nsobya, J.: Use of Internet and electronic data bases by health workers in Albert Cook Medical Library. Unpublished Bachelor (of Lib. \& Info. Sc.) dissertation, Makerere University, Kampala, Uganda (2002)

Nyakoojo, S.A.: Training and individual learning at Makerere University Business School. Unpublished Bachelor (of Business Adm.) dissertation, Makerere University, Kampala, Uganda (2002)

Obbo, D.F.: Gender and internet: Analysis of the portrayal of gender in Uganda websites on Internet. Unpublished Masters (of Sc in Info Sc) dissertation, Makerere University, Kampala, Uganda (2001) 
Rogers, E.M.: Diffusion of innovations, 5th edn. Free Press, NY (2003)

Schiffman, L.G., Kamik, L.L.: Consumer behaviour, 8th edn. Prentice-Hall of India, New Delhi (2004)

Sentamu, F.X.: Information technology, organizational culture and performance of National Water and Sewerage Corporation. Unpublished Masters (of Bus. Adm.) dissertation, Makerere University, Kampala, Uganda (2001)

Sseguya, H.: Factors that affect adoption of soil fertility management technologies in bananabased agriculture of the L. Victoria Basin. Unpublished Masters (of Sc. Agric Ext./ Educ.) dissertation, Makerere University, Kampala, Uganda (2000)

Sweet, S.A., Grace-martin, K.: Data analysis with SPSS:a first course in applied Statistics, 2nd edn. Allyn \& Bacon, Boston (2003)

Turban, E., Aronson, J.E., Liang, T., Sharda, R.: Decision support and business Intelligence systems, 8th edn. Pearson/ Prentice-Hall, NJ (2007)

Turyaheebwa, E.G.: Factors influencing KAP of modern contraception among women in Kampala District. Unpublished Masters (of Arts, Demo.) dissertation, Makerere University, Kampala, Uganda (2000)

Zziwa, G.: Computer utilization in management of students' information at Makerere. Unpublished Masters (of Arts in Educ. Mgt.) dissertation, Makerere University, Kampala, Uganda (2001) 